\title{
Peripheral Vascular Disease in Women: Therapeutic Options in 2019
}

Ammar Saati, $M D^{1}$

Noora AlHajir, MD, MPH

Lina Yaqoub, $M D^{3}$

Waqar Ahmed, $M D^{4}$

Mirvat Alasnag, $M D^{4, *}$

\author{
Address \\ ${ }^{1}$ Kent Hospital, Providence, RI, USA \\ ${ }^{2}$ Division of Cardiovascular Science, National Institute of Health/National Insti- \\ tute of Aging (NIH/NIA), Baltimore, MD, USA \\ ${ }^{3}$ Louisiana State University, Shreveport, LA, USA \\ ${ }^{*} 4$ Cardiac Center, King Fahd Armed Forces Hospital, P0 Box 9862, Jeddah, 21159, \\ Saudi Arabia \\ Email: mirvat@jeddacath.com
}

Published online: 14 November 2019

(C) The Author(s) 2019

This article is part of the Topical Collection on Women's Health

Keywords Peripheral vascular disease · Women · Endovascular revascularization · Surgery

\section{Abstract}

Purpose of review In recent years, there have been advances in the prevention, management, and control of peripheral vascular disease (PVD). There is a trend towards aggressive risk factor modification, noninvasive screening, and endovascular revascularization with surgical approaches reserved only for select cases. This article reviews the different management strategies ranging from pharmacotherapy, revascularization, and rehabilitation with an emphasis on the response of women to these therapies.

Recent findings Overall, the representation of women in the majority of the published data in this arena remains poor. Studies examining medical therapy and endovascular and surgical revascularization were not designed to address sex disparities. Nevertheless, we dissect these therapies and their relevant randomized trials.

Summary The paucity of data investigating the response of women to the different management options makes it difficult to make any evidence-based recommendations. This not only applies to the type of intervention, but also the appropriate timing and risks entailed. 
The main management goals for PVD are similar for both sexes, namely, reducing morbidity and mortality and improving symptoms and quality of life [1]. These goals are achieved by aggressive risk factor modification, pharmacotherapy, revascularization, and rehabilitation. The objective of this review is to describe such management strategies and examine their response in women specifically.

\section{Medical therapy}

The management of comorbidities such as diabetes mellitus with a target $\mathrm{Hb}_{\mathrm{A} 1 \mathrm{c}}$ between 6.0-7.0, hypertension, and dyslipidemia with statins is essential to reducing cardiovascular mortality and morbidity. Statin use may also improve walking distance and speed in patients with claudication [2-4]. Smoking cessation slows the progression to critical leg ischemia and reduces the risk of myocardial infarction and death from related events [5]. The HERS trial revealed that women who were on hormonal replacement therapy (HRT) and used statins had a reduced risk of thromboembolic events when compared to those who did not [6]. It is noteworthy that based on several studies, pharmacological therapy is underused in women. Statin use in women is 63\% compared to $87 \%$ in men; the use of antiplatelet agents is $40 \%$ in women compared to $58 \%$ in men $[7,8]$. Compared to women, the odds of men seeking and receiving lipid lowering agents is 1.3 and for antiplatelet agents is 1.6 [9]. Similarly, there is lower use of ACE inhibitors in women. Overall, men are more likely to receive multiple agents compared to women [10].

Although pharmacotherapy and life-style modification are imperative for reduction of mortality and morbidity, they may not provide significant reduction of claudication. Agents that are specifically prescribed for symptom relief include Cilostazole, Naftidrofuryl, and Carnitine. Results from four randomized controlled trials found that Cilostazole can improve pain-free walking distance, functional capacity, ankle brachial index, and raise serum HDL cholesterol concentration level [11-14]. There are no trials that specifically address the effects of these agents in women. The overall sample size of the majority of these trials was small and enrollment of women was $20-30 \%$.

The role of antiplatelet therapy on the progression of PVD remains unclear. The CAPRIE study found that clopidogrel reduced the risk of myocardial infarction, stroke, and mortality rate by $24 \%$ when compared to patients who received aspirin alone [4]. Aspirin had a numerical, but not statistically significant, reduction in the risk of myocardial infarction, stroke, and death from vascular causes. Accordingly, the Food and Drug Administration (FDA) expert panel found insufficient evidence to approve the labeling of aspirin for PVD [5].

Rivaroxaban is an oral direct factor Xa inhibitor approved by the FDA for the prevention of atherothrombotic events in adults with stable coronary artery disease or symptomatic PVD who are at high risk of ischemic events, based on the COMPASS study. Rivaroxaban $2.5 \mathrm{mg}$ twice daily combined with aspirin $100 \mathrm{mg}$ significantly reduced the risk of stroke $(42 \%)$, cardiovascular death $(22 \%)$, and heart attacks (14\%) compared to aspirin alone. The enrollees of this trial were 27,395 in total. Disappointingly, women constituted only $23 \%$ of the total studied population $[15,16]$.

\section{Endovascular therapy}

Indications for revascularization therapy include critical limb ischemia (CLI), rest pain, gangrene, or refractory claudication [17]. Historically, surgery had been the revascularization choice in these patients. However, women tended to have worse clinical outcomes after surgical revascularization mainly due to postprocedural complications, including bleeding and infection. With advancements in endovascular techniques over the past decade, there has been a paradigm shift in the treatment of PVD [18-20]. Traditionally, percutaneous vascular intervention (PVI) is recommended for type A or B Transatlantic InterSociety Consensus (TASCII), those with favorable anatomy or those who are not surgical candidates or would have significant morbidity with surgery [21].

\section{Percutaneous transluminal angioplasty}

Percutaneous transluminal angioplasty (PTA) is an appropriate option for iliac and superficial femoral artery (SFA) lesions. In iliac occlusive disease, studies have shown better outcomes with PTA and stenting compared with PTA alone. Interestingly, although women tend to present at an older age with iliac disease and have more extensive occlusive disease, PVI outcomes and stent patency did not differ in women compared to men $[17,20,22]$. SFA lesions longer than $10 \mathrm{~cm}$ are best treated with PTA and stenting as studies have demonstrated better patency rates compared to PTA alone. 
However, the femoral artery stenting trial (FAST) revealed that lesions shorter than $10 \mathrm{~cm}$ treated with PTA only without stenting had comparable outcomes to stenting [23]. Enrollment of women in this trial was $25 \%$ only.

PVI is usually avoided in the common femoral and popliteal arteries due to the high failure rates observed in these locations; this is mainly attributed to higher flexion leading to stent fracture or dissociation [17]. For infrapopliteal lesions in CLI, balloon angioplasty is recommended as the treatment of choice with stenting reserved for refractory or calcified lesions [17, 24, 25]. The ACHILLES trial randomized 200 patients to stenting using a sirolimus-eluting stent (SES) or balloon angioplasty. Results at 1 year demonstrated lower angiographic restenosis rates $(22.4 \%$ vs. $41.9 \%, p=0.019)$, greater vessel patency $(75.0 \%$ vs. $57.1 \%, p=0.025)$, and similar death, repeat revascularization, index-limb amputation rates, and proportions of patients with improved Rutherford class for SES versus PTA [26]. Once again, the enrollment of women was low with $25-33 \%$ in each arm. Irrespective of sex, it is important to note that when patients present with single vessel run off, weighing the risks and benefits of intervention is critical as the intervention itself can precipitate acute limb ischemia by embolic or thrombotic events $[17,25]$.

The K-VIS ELLA (Korean Vascular Intervention Society Endovascular Therapy in Lower Limb Artery Disease) registry is a nationwide, multicenter, observational study that included 3073 PVD patients undergoing PVI. A total of 2523 men and 550 women were enrolled. The primary outcome was a composite of death, myocardial infarction, and major amputation. Investigators reported more comorbidities and more severe and complex target lesions in women than men. Compared to men, women had higher rates of death, myocardial infarction, major amputations $(14.8 \%$ versus $9.8 \%, P=0.038)$, major adverse limb events $(19.9 \%$ versus $14.5 \%, P=$ $0.039)$, and procedural complications $(10.2 \%$ versus $5.9 \%, P<0.001)$. The primary outcome was significantly higher in women with claudication compared to men $(P<0.001)$. In contrast, there was no significant difference in primary outcome for patients with critical limb ischemia between men and women $(P=0.426)[27 \bullet]$.

\section{Drug-coated balloons and stents}

In recent years, drug-eluting technologies have raised expectations for the treatment of femoro-popliteal disease. Studies have shown that there are clear advantages to drug-coated balloons (DCB) and drug-eluting stents
(DES) using paclitaxel as shown in 5-year outcome studies for both devices $[28 \bullet, 29 \bullet, 30]$.

The THUNDER study was designed to investigate the effect of local paclitaxel administration using a DCB on restenosis rates after femoro-popliteal arterial interventions. A total of 154 patients were randomized in this multicenter trial [29•]. The study had a pre-specified analysis to examine sex-based differences in outcome. The study demonstrated that the cumulative number of patients with at least 1 target lesion revascularization (TLR) was lower in the DCB arm. In the control group, TLR was necessary in 30 of 54 of the patients $(56 \%)$ compared with 10 of $48(21 \%)$ in the DCB group ( $p$ $<0.0005)$. An exploratory sex analysis found a cumulative TLR rate that was lower in men than in women (4 of 24 patients [17\%] vs. 6 of 16 patients [38\%]). The cumulative 5-year TLR rate in the control group was slightly higher for men (20 of 28 patients [ $71 \%$ ] vs. 10 of 19 patients [52\%]). Given that women account for a growing percentage of the elderly population presenting with PVD, the authors comment that their exploratory analysis is limited by the small number of patients but showed a similar trend as in the PACIFIER study in which the long-term benefit of DCB appears to be greater in men than women [30]. The absolute numbers remain small and should be tested in larger studies.

In contrast to the very positive results of femoropopliteal disease with drug-coated devices, similar success was not met in infrapopliteal disease. The BIOLUX P-II compared the Biotronic Passeo-18 LUX DCB versus an uncoated balloon in 72 patients with infrapopliteal disease. The sex of the 36 subjects in each arm is not reported. The primary outcomes did not differ significantly between patients treated with DCB and patients treated with PTA. The authors concluded that the primary study hypothesis, a $45 \%$ relative risk reduction for binary restenosis, was not met [31]. However, there was no signal for worse outcomes as detected in the IN.PACT Deep study in which there was a trend towards an increased major amputation rate through 12 months compared to PTA [32].

The Zilver PTX randomized control trial included long-term follow-up for the Zilver DES through 5 years [28•]. It is the largest randomized SFA endovascular device trial reported, and the 5-year outcomes provide the longest known comparative outcomes of DES to standard endovascular treatment for femoro-popliteal disease. Four hundred seventy-nine patients underwent randomization to DES versus control PTA, followed by second randomization of the acute PTA failures to a bare 
metal stent (BMS) versus the study DES. Thirty-five percent of the patients in both arms were women. The primary endpoint was very positive in favor of DES versus PTA (including BMS for acute PTA failures). The primary patency rate was $66.4 \%$ in the DES arm versus $44.1 \%$ in the PTA arm $(P<0.01)$. The 5-year outcome study did not report any specific subgroup interactions including sex differences.

The latest stent in the peripheral market for femoropopliteal disease is the Eluvia stent which is a polymercoated paclitaxel-eluting stent. This was tested in a head to head comparison with the Zilver PTX DES in the IMPERIAL study [33•]. This is the only randomized study of two DES in the peripheral circulation. Four hundred fifty-six patients were randomized to Zilver PTX or the Eluvia stent. Women constituted 34\% of the study population. Primary patency at 12 months was $87 \%$ in the Eluvia group and $82 \%$ in the Zilver PTX stent group (difference 5.3\%; $p<0 \cdot 0001$ ). Target lesion revascularization in the Eluvia group was half of that in the Zilver PTX group. While the study was powered to show non-inferiority for the Eluvia stent, it showed a trend towards superiority. This trial did not address sex disparity in the analysis.

\section{Recent controversy}

The very encouraging result of the DCB and DES studies in the femoro-popliteal arteries was tempered by the surprising report of Katsanos et al. It is a summary level meta-analysis of 28 studies of the paclitaxel-coated DCB and DEB. Investigators reported an increase in the relative risks of mortality with paclitaxel-coated devices. In light of this controversy the FDA issued a Letter to Health Care Providers on March 5, 2019, and updated on April 23, 2019 [34]. Since then, multiple patient-level meta-analyses have been published and do not show any trend towards increased mortality $[35 \bullet, 36 \bullet \bullet, 37 \bullet \bullet]$. In addition, Secemsky et al. analyzed Medicare patients, with a median follow-up time of 2 years of BMS versus DES. They found no difference in mortality for DES versus BMS [38].

The FDA letter best summarizes the current state of affairs:

"These data should be interpreted with caution for several reasons. First, there is large variability in the risk estimate of mortality due to the limited amount of longterm data. Second, these studies were not originally designed to be pooled, introducing greater uncertainty in the results. Third, the specific cause and mechanism of the increased mortality is unknown."

\section{Endovascular atherectomy}

Several atherectomy devices have been approved as debulking therapies in PVD. The first of such devices is the Silverhawk which has been modified to the more recent generation HawkOne device. The DEFINITIVE LE (Lower Extremity Revascularization Using Directional Atherectomy: 12-Month Prospective Results) Study is the most recent trial examining atherectomy in infrainguinal disease. A pre-specified subgroup analysis for diabetic patients was provided. A total of 800 subjects were enrolled (of which $45 \%$ were women). The 12 -month primary patency was $78 \%$ in claudicants (77\% in the diabetic subgroup versus $78 \%$ in the nondiabetic subgroup). The rate of freedom from major unplanned amputation of the target limb at 12 months in CLI subjects was 95\%. Adverse event included embolization (3.8\%), perforation (5.3\%), and abrupt closure $(2.0 \%)$. The bailout stent rate was 3.2\% [39•].

Shammas et al. also examined directional atherectomy in their 2011 publication. The primary endpoint of their study was TLR at 1 year. During follow-up, TLR rates were similar in the atherectomy and angioplasty arms (11.1 vs. $16.7 \%$ ), with a small numerical benefit in favor of directional atherectomy. However, atherectomy plus angioplasty resulted in significantly less bailout stenting due to suboptimal immediate technical result ( 27.6 vs. $62.1 \% ; p=0.017$ ). On the other hand, distal macro-embolization was significantly higher in the atherectomy arm (64.7 vs. $0.0 \% ; p<0.001)$ [40].

Orbital atherectomy was investigated by the same group. Procedural success was detected in $93 \%$ of the atherectomy plus angioplasty arm vs. angioplasty alone $82.4 \%$. Bailout stenting was needed in $6.9 \%$ of the atherectomy plus angioplasty vs. angioplasty alone $14.3 \%$. At 1-year follow-up, no patient underwent major amputation. Freedom from TVR and all-cause mortality rates were 93.3 and $100 \%$ in the atherectomy plus balloon angioplasty arm versus $80.0 \%$ and $68.4 \%$ in the balloon angioplasty alone arm, respectively [41].

Excimer laser atherectomy (ELA) was examined in a study of 250 patients in 2015. The trial included those with claudication or CLI (Rutherford Class 1 to 4 ) due to in-stent restenosis. Primary efficacy endpoint was 6month TLR and primary safety endpoint was 30-day 
major adverse event (death, amputation, or TLR). Although the calcifications were significantly higher in the atherectomy arm (27.1 vs. 9.1\%), ELA resulted in superior procedural success (93.5 vs. $82.7 \% ; p=0.01$ ) and freedom from TLR (73.5 vs. 51.8\%; $p<0.005)$, significantly fewer procedural complications and 30day major adverse event rates (5.8 vs. $20.5 \%$; $p<$ 0.001 ), respectively. Moreover, ELA was associated with a 52\% TLR reduction [42].

In 2014, Diamantopoulos et al. elaborated a metaanalysis of six randomized trials that summarized the outcomes of atherectomy. It suggested that there was no advantage to debulking atherectomy compared to plain balloon angioplasty alone. The meta-analysis was, however, limited to 287 patients [43]. None of the atherectomy trials addressed sex disparities specifically. Post hoc analysis of these trials is not possible given the small numbers enrolled overall and women particularly.

\section{Endovascular repair of the aorta}

Large trials have evaluated the role of screening for abdominal aortic aneurysm (AAA) in men. These trials have demonstrated a reduction in aneurysm-related death as well as cost effectiveness of screening [44-49]. Accordingly, the United States Preventive Services Task Force (USPSTF) recommends screening for men between the age of 65 and 75 years with history of smoking [50]. It has generally been accepted that the prevalence of AAA in women is low, $20 \%$ of that in men. History of smoking, age more than 65 years, and history of heart disease have been identified as risk factors that require screening in women [44]. However, screening protocols remain unclear for women.

When examining sex disparities in AAA management, there are several confounders. Firstly, the data is primarily derived from screened populations. It is established that screened aneurysms in men have a better prognosis compared to non-screened cohorts. Therefore, data derived solely from screened populations may be misleading in both sexes. Indexing diameters in men has been standardized and proven useful in determining the time for intervention. This has not been addressed in randomized trials for women. Theoretically, indexing in women may lower the threshold and subject them to premature intervention. Although aneurysms are less frequent in women, they have worse outcomes. It remains unknown whether early screening and intervention will reduce mortality.
Furthermore, in view of more complex anatomy, rapid rate of aneurysm expansion and a higher rate of rupture at smaller diameters, women are at increased risk of death from an AAA [51]. They also have a higher 30-day mortality rate and more complications from either open abdominal aortic aneurysm repair or endovascular repair (EVAR) than men [52]. In terms of EVAR, 60\% of women are not suitable candidates for treatment with conventional devices. On average, the infrarenal aortic neck length in women is $12 \mathrm{~mm}$ and $16 \mathrm{~mm}$ in men. The neck angulation in women is $45^{\circ}$ and $36^{\circ}$ in men. The iliac arteries' diameter in women is $11 \mathrm{~mm}$ and $14 \mathrm{~mm}$ in men. Currently available devices have taken into account these anatomic differences and are often tailored for specific patient measurements. Specific manufacturers address short neck, angulation, and low profiles [53•].

Trials such as the LIFE Study explored benefits of a minimalistic approach using the low-profile TriVascular Ovation Prime device [54, 55]. This includes percutaneous access, conscious sedation, and next-day discharge from the hospital. Results at 30 days demonstrated low rates of adverse events, high procedural success rates, freedom from endoleak, and hospital readmission rates 5 times lower than those with contemporary EVAR protocols $(1.6 \%$ vs $8.2 \%)$. The LUCY trial addressed outcomes of a minimalistic approach using the Ovation Prime device specifically in women [56]. A total of 225 patients were enrolled, 76 women and 149 men. LUCY 1-year data revealed that at least $28 \%$ more women were eligible for EVAR when using the Ovation abdominal stent graft system than when using other EVAR systems. The primary endpoint of the study was defined as the 30-day major adverse event rate. Despite more complex anatomy, women had similar outcomes compared to men at 1-year. In both men and women, freedom from rupture was $100 \%$, from conversion was $100 \%$, and from all device-related reintervention was $97.2 \%$. Freedom from AAA-related morality was $100 \%$ in women and $98.6 \%$ in men.

In their meta-analysis, Ulug et al. concluded that compared to men, fewer women were eligible for EVAR (34\% vs 54\%), fewer women were offered intervention (34\% vs $19 \%$ ), and the 30 -day mortality was higher in women for both EVAR (23\% vs 14\%) and open repair ( $54 \%$ vs $28 \%$ ). Randomized data elucidating the role of screening, indexing, and early repair in women is necessary $[53 \bullet]$.

\section{Surgical intervention}

Surgical revascularization should be recommended when an endovascular approach is not feasible from 
an anatomical perspective or when it fails [57]. Surgical revascularization outcome trials are largely obtained from predominantly male populations. Only 32\% of randomized trial participants for PVD revascularization were women (range 0-54\%). Women undergoing surgery for PVD in these trials were older, had advanced disease, and had a lower prevalence of smoking [58]. African-American women had higher early graft failure compared to white men. There was no significant difference in death, major or minor complications between women and men [59]. In an observational study, Ferranti et al. found no sex disparity in common femoral artery endarterectomy or arterial segment interventional treatment (Aortoiliac, Superficial femoral artery popliteal bypass, Infrapopliteal, Multiple grafts) [60]. With regard to infrainguinal disease, there are multiple conflicting results. In several observational studies for critical limb ischemia, surgical outcomes defined as MACE (including death), amputation, and a second intervention were identical for both sexes [61, 62]. However, Lejay et al. published their retrospective data in 2015 concluding that women were at higher risk of adverse events [63]. This may be attributed to the older age of women enrolled in this cohort. Additionally, unlike other trials, in this trial, women and men had comparable risk factors, comorbidities, medications, extent of lesions, types of bypass, and conduits ensuring homogeneity of both groups.

Management of PVD has changed after endovascular revascularizations, and the number of open surgeries dropped by $32 \%$ and major amputation decreased noticeably by $35 \%$ in women and $21 \%$ in men [64]. In their meta-analysis, Wan et al. evaluated the effect of sex on outcomes after surgery. The investigators concluded that women had inferior short-term outcomes for 30day reintervention and higher 30-day mortality, amputations, early graft thrombosis, embolization, cardiac and pulmonary events, and stroke. With regard to long-term outcomes, namely survival, graft patency, and limb salvage, no difference between women and men was detected [65].

\section{Amputations}

Fifty-four percent of all amputations are attributable to PVD. Women constitute $47 \%$ of all amputations. It is projected that the number of people living with an amputated limb will more than double by the year 2050 [66]. Although women have a lower prevalence of amputations, they remain at higher risk compared to men [67]. A large longitudinal study of Critical Limb Ischemia, from 2002 to 2011 by the Health Utilization Project Nationwide Inpatient Sample, found that Women maintained a higher ratio of above-knee amputation to below-knee amputations compared to men. This was associated with a higher mortality, increased functional impairment, and poor quality of life [67].

\section{Rehabilitation/Exercise Program}

Supervised Exercise Program (SEP) at least 3 times per week, 30-60 $\mathrm{min}$, for at least 12 weeks is essential in the management of patients with claudication [68]. The CLEVER study (Supervised Exercise versus Primary Stenting for Claudication From Aortoiliac Peripheral Artery Disease) concluded that SEP provides superior improvement in treadmill walking performance over 6 months compared to stent revascularization therapy and optimal medical care for both sexes. It is notable that the optimal medical care arm was $73 \%$ male predominate and the stent therapy plus medical care only had 30\% women [69]. When combining SEP with endovascular revascularization, walking distance was increased to $566 \mathrm{~m}$ compared to $402 \mathrm{~m}$ in endovascular group alone. Following bypass surgery, SEP had an $89 \%$ improvement in the 6 min walking test compared to $47 \%$ in bypass surgery alone. Generally, a 12 -week SEP before or after intervention may reduce cardiovascular mortality [70]. Most of the studies conducted on SEP were based on studies with male predominance. Enrollment of women ranged from 0 to $48 \%$ (average 26\%). None reported sex-specific analyses or outcomes [58].

\section{Guidelines overview}

The American Heart Association and American College of Cardiology elaborated an update in 2016 on PVD guidelines. In 2017, the European Society of Cardiology along with the European Society for Vascular Surgery, issued comprehensive guidelines for the management of PVD. Both guidelines emphasize the importance of lowering risk factors and optimizing medical management with particular attention to smoking cessation, lipid, blood pressure, and glucose control (class I). Concerning diagnosis both societies recommend a resting ankle brachial index as a first line study (class I). The US guidelines recommend targeted screening for individuals with one of the following criteria: age $>65$, age 50-64 with risk factors or family history of PVD, age < 50 with diabetes and one other additional risk factor, or patients with other atherosclerotic vascular disease. Both 
guidelines recommend against ultrasound Doppler, computed tomography angiography, Magnetic resonance angiography, or catheter-based angiography imaging for initial diagnosis.

As for medical treatment, both guidelines recommend antiplatelet therapy either aspirin or clopidogrel in symptomatic PVD (class I); however, the European guidelines prefer clopidogrel over aspirin (class IIb). Cilostazol was favored by the US guidelines for reducing symptoms during exercise [71], and categorized it as a class I recommendation. In contrast, the European guidelines reported limited effect and did not recommend cilostazol therapy. SEP therapy is a (class I) recommendation in both guidelines. Revascularization, either endovascular or surgical bypass, for patients with intermittent claudication, after failure of guideline directed medical therapy and exercise, is considered a class IIa recommendation in both guidelines. The primary difference between the two guidelines in revascularization lies in that the US guidelines emphasize postprocedure surveillance and wound care. On the other hand, the European guidelines focus on revascularization strategies and contemporary therapies. An important limitation acknowledged by the European guidelines is that women were underrepresented in research

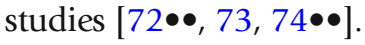

\section{Compliance with Ethical Standards}

Conflict of Interest

The authors declare that they have no conflicts of interest.

Human and Animal Rights and Informed Consent

This article does not contain any studies with human or animal subjects performed by any of the authors.

\section{Open Access}

This article is distributed under the terms of the Creative Commons Attribution 4.0 International License (http://creativecommons.org/licenses/by/4.0/), which permits unrestricted use, distribution, and reproduction in any medium, provided you give appropriate credit to the original author(s) and the source, provide a link to the Creative Commons license, and indicate if changes were made.

\section{References and Recommended Reading}

Papers of particular interest, published recently, have been highlighted as:

- Of importance

$\bullet \quad$ Of major importance

1. Hiatt WR. Medical treatment of peripheral arterial disease and claudication. (Review Article). N Engl J Med. 2001;344(21):1608-21.

2. Lonn E, Roccaforte R, Yi Q, et al. Effect of long-term therapy with ramipril in high-risk women. J Am Coll Cardiol. 2002;40(4):693-702.

3. Giri J, Mcdermott MM, Greenland P, et al. Statin use and functional decline in patients with and without peripheral arterial disease. J Am Coll Cardiol. 2006;47(5):998-1004.

4. Brunelle C, Mulgrew J. Exercise for intermittent claudication. Phys Ther. 2011;91(7):997-1002.

5. Teodorescu VJ, Vavra AK, Kibbe MR. Peripheral arterial disease in women. J Vasc Surg. 2012;57(4):18S-26S.
6. Herrington MD, Vittinghoff G, Eric L, Feng S, et al. Statin therapy, cardiovascular events, and total mortality in the Heart and Estrogen/Progestin Replacement Study (HERS). Circulation. 2002;105(25):2962-7.

7. Norgren L, Hiatt WR, Dormandy JA, Nehler MR, Harris KA, Fowkes FGR. Inter-society consensus for the management of peripheral arterial disease (TASC II). J Vasc Surg. 2007;45(Suppl S):S5-67.

8. Cheanvechai V, Harthun NL, Graham LM, Freischlag JA, Gahtan V. Incidence of peripheral vascular disease in women: is it different from that in men? J Thorac Cardiovasc Surg. 2004;127:314-7.

9. Sigvant B, Wiberg-Hedman K, Bergqvist D, Rolandsson O, Wahlberg E. Risk factor profiles and use of 
cardiovascular drug prevention in women and men with peripheral arterial disease. Eur J Cardiovasc Prev Rehabil. 2009;16:39-46.

10. Paquet M, Pilon D, Tetrault JP, Carrier N. Protective vascular treatment of patients with peripheral arterial disease: guideline adherence according to year, age and gender. Can J Public Health. 2010;101:96-100.

11. Dawson DL, Cutler BS, Meissner MH, Strandness DE. Cilostazol has beneficial effects in treatment of intermittent claudication: results from a multicenter, randomized, prospective, double-blind trial. Circulation. 1998;98(7):678-86.

12. Money SR, Herd JA, Isaacsohn JL, Davidson M, Cutler B, Heckman J, et al. Effect of cilostazol on walking distances in patients with intermittent claudication caused by peripheral vascular disease. J Vasc Surg. 1998;27(2):267-75.

13. Beebe HG, Dawson DL, Cutler BS, Herd JA, Strandness $\mathrm{DE}$, Bortey EB, et al. A new pharmacological treatment for intermittent claudication: results of a randomized, multicenter trial. Arch Intern Med. 1999;159(17):2041-50.

14. Dawson DL, Cutler BS, Hiatt WR, Hobson RW II, Martin JD, Bortey EB, et al. A comparison of cilostazol and pentoxifylline for treating intermittent claudication. Am J Med. 2000;109(7):523-30.

15. Nunnelee JD. Review of an article: oral rivaroxaban for symptomatic venous thromboembolism. The EINSTEIN Investigators et al. N Engl J Med. 2010;363(26):2499-510.

16. U.S. FDA Approves XARELTO ${ }^{\circledR}$ (rivaroxaban) to reduce the risk of major cardiovascular events in patients with chronic coronary artery disease (CAD) or peripheral artery disease (PVD). PR Newswire. http://search. proquest.com/docview/2117932094/. Published October 11, 2018.

17. Schramm K, Rochon PJ. Gender differences in peripheral vascular disease. Semin Interv Radiol. 2018;35:009-16.

18. Jain AK, Velazquez-Ramirez G, Goodney PP, Edwards MS, Corriere MA. Gender-based analysis of perioperative outcomes associated with lower extremity bypass. Am Surg. 2011;77:844-9.

19. Egorova N, Vouyouka AG, Quin J, Guillerme S, Moskowitz A, Marin M, et al. Analysis of gender-related differences in lower extremity peripheral arterial disease. J Vasc Surg. 2010;51:372-8.e1; discussion 378-9.

20. Jackson EA, Munir K, Schreiber T, Rubin JR, Cuff R, Gallagher KA, et al. Impact of sex on morbidity and mortality rates after lower extremity interventions for peripheral arterial disease: observations from the Blue Cross Blue Shield of Michigan Cardiovascular Consortium. J Am Coll Cardiol. 2014;63:2525-30.

21. Norgren L, Hiatt WR, Dormandy JA, Nehler MR, Harris KA, Fowkes FG, et al. Inter-society consensus for the Management of Peripheral Arterial Disease (TASC II). Eur J Vasc Endovasc Surg. 2007;33(Suppl 1):S1-75.

22. Pulli R, Dorigo W, Pratesi G, Fargion A, Angiletta D, Pratesi C. Gender-related outcomes in the endovascular treatment of infrainguinal arterial obstructive disease. J Vasc Surg. 2012;55:105-12.

23. Krankenberg H, Schluter M, Steinkamp HJ, Burgelin K, Scheinert D, Schulte KL, et al. Nitinol stent implantation versus percutaneous transluminal angioplasty in superficial femoral artery lesions up to $10 \mathrm{~cm}$ in length: the femoral artery stenting trial (FAST). Circulation. 2007;116:285-92.

24. Romiti M, Albers M, Brochado-Neto FC, Durazzo AE, Pereira CA, De Luccia N. Meta-analysis of infrapopliteal angioplasty for chronic critical limb ischemia. J Vasc Surg. 2008;47:975-81.

25. Schmidt A, Ulrich M, Winkler B, Klaeffling C, Bausback Y, Braunlich S, et al. Angiographic patency and clinical outcome after balloon-angioplasty for extensive infrapopliteal arterial disease. Catheter Cardiovasc Interv. 2010;76:1047-54.

26. Scheinert D, Katsanos K, Zeller T, Koppensteiner R, Commeau $\mathrm{P}$, Bosiers $\mathrm{M}$, et al. A prospective randomized multicenter comparison of balloon angioplasty and infrapopliteal stenting with the sirolimus-eluting stent in patients with ischemic peripheral arterial disease: 1-year results from the ACHILLES trial. J Am Coll Cardiol. 2012;60:2290-5.

27. Choi KH, Park TK, Kim J, Ko Y, Yu CW, Yoon C, et al. J Am Heart Assoc. 2019;8(2):e01084.

Nationwide registry specifically examining outcomes of endovascular revascularization in women.

28.• Dake MD, Ansel GM, Jaff MR, Ohki T, Saxon RR, Smouse HB, et al. Durable clinical effectiveness with paclitaxel-eluting stents in the femoropopliteal artery: 5 -year results of the Zilver PTX randomized trial. Circulation. 2016;133(15):1472-8.

Contemporary RCT examining outcomes of DES in Femoropopliteal vessels.

29. Tepe G, Schnorr B, Albrecht T, et al. Angioplasty of femoral-popliteal arteries with drug-coated balloons: 5 -year follow-up of the THUNDER trial. JACC Cardiovasc Interv. 2015;8(1 Pt A):102-.

Contemporary RCT examining outcomes of DCB in Femoropopliteal vessels.

30. Werk M, Albrecht T, Meyer DR, Ahmed MN, Behne A, Dietz U, et al. Paclitaxel-coated balloons reduce restenosis after femoro-popliteal angioplasty: evidence from the randomized PACIFIER trial. Circ Cardiovasc Interv. 2012;5:831-40.

31. Zeller T, Beschorner U, Pilger E, Bosiers M, Deloose K, Peeters $\mathrm{P}$, et al. Paclitaxel-coated balloon in infrapopliteal arteries. 12-month results from the BIOLUX P-II randomized trial. J Am Coll Cardiol Intv. 2015;8:1614-22.

32. Zeller T, Baumgartner I, Scheinert D, Brodmann M, Bosiers M, Micari A, et al. Drug-eluting balloon versus standard balloon angioplasty for infrapopliteal arterial revascularization in critical limb ischemia: 12-month results from the IN.PACT DEEP randomized trial. J Am Coll Cardiol. 2014;64:1568-76.

33. Gray WA, Keirse K, Soga Y, Benko A, Soga Y, Benko A, et al. A polymer-coated, paclitaxel-eluting stent 
(Eluvia) versus a polymer-free, paclitaxel-coated stent (Zilver PTX) for endovascular femoropopliteal intervention (IMPERIAL): a randomised, non-inferiority trial. Lancet. 2018;392:1541-5.

Contemporary RCT examining two different DES.

34. Zeller T, Baumgartner I, Scheinert D, Brodmann M, Bosiers M, Micari A, et al. Drug-eluting balloon versus standard balloon angioplasty for infrapopliteal arterial revascularization in critical limb ischemia: 12-month results from the IN.PACT DEEP randomized trial. J Am Coll Cardiol. 2014;64:1568-76.

35.• Katsanos K, Spiliopoulos S, Kitrou P, Krokidis M, Karnabatidis D. Risk of death following application of paclitaxel-coated balloons and stents in the femoropopliteal artery of the leg: a systematic review and meta-analysis of randomized controlled trials. J Am Heart Assoc. 2018;7(24):e01124.

Metanalysis that raised concern over higher mortality with Paclitaxel devices.

$36 . \bullet \quad$ U.S. Food \& Drug Administration (2019) Treatment of peripheral arterial disease with paclitaxel-coated balloons and paclitaxel-eluting stents potentially associated with increased mortality - Letter to Health Care Providers. Retrieved from https://www.fda.gov/ MedicalDevices/Safety/LetterstoHealthCareProviders/ ucm633614.htm. Accessed 5/15/19.

Response of USFDA to the Paclitaxel controversy.

37.• Schneider PA, Laird JR, Doros G, et al. Mortality not correlated with paclitaxel exposure: an independent patient-level meta-analysis. J Am Coll Cardiol. 2019.

Very recent independent Meta-analysis addressing the Paclitaxel controvery.

38. Secemsky EA, Kundi H, Weinberg I, Jaff MR, Krawisz A, Parikh SA, et al. Association of survival with femoropopliteal artery revascularization with drugcoated devices. JAMA Cardiol. 2019;4:332-40.

39. Rastan A, McKinsey JF, Garcia LA, Rocha-Singh KJ, Jaff MR, Harlin S, et al. One-year outcomes following directional atherectomy of popliteal artery lesions: subgroup analysis of the prospective, multicenter DEFINITIVE LE trial. J Endovasc Ther. 2018;25(1):100-.

RCT examining role of atherectomy.

40. Shammas NW, Coiner D, Shammas GA, Dippel EJ, Christensen L, Jerin M. Percutaneous lower-extremity arterial interventions with primary balloon angioplasty versus Silverhawk atherectomy and adjunctive balloon angioplasty: randomized trial. J Vasc Interv Radiol. 2011;22(9):1223-8.

41. Shammas NW, Lam R, Mustapha J, Ellichman J, Aggarwala G, Rivera E, et al. Comparison of orbital atherectomy plus balloon angioplasty vs. balloon angioplasty alone in patients with critical limb ischemia: results of the CALCIUM 360 randomized pilot trial. J Endovasc Ther. 2012;19(4):480-8.

42. Dippel EJ, Makam P, Kovach R, George JC, Patlola R, Metzger DC, et al. Randomized controlled study of excimer laser atherectomy for treatment of femoropopliteal in-stent restenosis: initial results from the EXCITE ISR trial (EXCImer laser randomized controlled study for treatment of femoropopliteal instent restenosis). JACC Cardiovasc Interv. 2015;8:92101.

43. Diamantopoulos A, Katsanos K. Atherectomy of the femoropopliteal artery: a systematic review and metaanalysis of randomized controlled trials. J Cardiovasc Surg. 2014;55(5):655-65.

44. DeRubertis BG, Trocciola SM, Ryer EJ, Pieracci FM, McKinsey JF, Pl F, et al. Abdominal aortic aneurysm in women: prevalence, risk factors, and implications for screening. J Vasc Surg. 2007;46(4):630-5.

45. Lederle FA, Johnson GR, Wilson SE, Chute EP, Littooy FN, Bandyk D, et al. Prevalence and associations of abdominal aortic aneurysm detected through screening. Aneurysm Detection and Management (ADAM) Veterans Affairs Cooperative Study Group. Ann Intern Med. 1997;126:441-9.

46. Ashton HA, Buxton MJ, Day NE, Kim LG, Marteau TM, Scott RA, et al. The Multicenter Aneurysm Screening Study (MASS) into the effect of abdominal aortic aneurysm screening on mortality in men: a randomized controlled trial. Lancet. 2002;360:1531-9.

47. Norman PE, Jamrozik K, Lawrence-Brown MM, Le MT, Spencer CA, Tuohy RJ, et al. Population based randomized controlled trial on impact of screening on mortality from abdominal aortic aneurysm. Br Med J. 2004;329:1259.

48. Scott RA, Wilson NM, Ashton HA, Kay DN. Influence of screening on the incidence of ruptured abdominal aortic aneurysm: 5-year results of a randomized controlled study. Br J Surg. 1995;82:1066-70.

49. Lee TY, Korn P, Heller JA, Kilaru S, Beavers FP, Bush HL, et al. The cost-effectiveness of a "quick-screen" program for abdominal aortic aneurysms. Surgery. 2002;132:399-407.

50. Fleming C, Whitlock EP, Beil TL, Lederle FA. Screening for abdominal aortic aneurysm: a best-evidence systematic review for the US Preventive Services Task Force. Ann Intern Med. 2005;142:203-11.

51. Solberg S, Singh K, Wilsgaard T, Jacobsen BK. Increased growth rate of abdominal aortic aneurysms in women. The Tromsø study. Eur J Vasc Endovasc Surg. 2005;29(2):145-9.

52. Sweeting MJ, Thompson SG, Brown LC, Powell JT, RESCAN collaborators. Metaanalysis of individual patient data to examine factors affecting growth and rupture of small abdominal aortic aneurysms. Br J Surg. 2012;99:655-65.

53. - Ulug P, Sweeting MJ, von Allmen RS, Thompson SG, Powell JT, on behalf of the SWAN collaborators. Morphological suitability for endovascular repair, non-intervention rates, and operative mortality in women and men assessed for intact abdominal aortic aneurysm repair: systematic reviews with metaanalysis. Lancet. 2017;389(10088):2482-91.

Meta-analysis of endovascular repair of the aorta.

54. Krajcer Z, Ramaiah VG, Huetter M, Miller LE. Fast-track endovascular aortic repair: interim report from the 
prospective LIFE registry. Catheter Cardiovasc Interv. 2016;88(7):1118-23.

55. Gupta PK, Fernandes-Taylor S, Ramanan B, Engelbert TL, Kent KC. Unplanned readmissions after vascular surgery. J Vasc Surg. 2014;59(2):473-82.

56. LUCY Study: TriVascular evaluation of females who are underrepresented candidates for abdominal aortic aneurysm repair (LUCY). Available at: https://

clinicaltrials.gov/ct2/show/NCT02479191 [2015 Jun 24; updated 2017 May 3].

57. Kullo IJ, Rooke TW. Peripheral artery disease. N Engl J Med. 2016;374(9):861-71.

58. Hirsch AT, Allison MA, Gomes AS, Corriere MA, Duval $S$, Ershow AG, et al. A call to action: women and peripheral artery disease. Circulation. 2012;125(11):1449-72.

59. Jain AK, Kalbaugh CA, Farber MA, Marston WA, Vallabhaneni R. Race and gender affect outcomes of lower extremity bypass. J Vasc Surg. 2014;60(5):127581.

60. Ferranti KM, Osler TM, Duffy RP, Stanley AC, Bertges DJ. Association between gender and outcomes of lower extremity peripheral vascular interventions. J Vasc Surg. 2015;62(4):990-7.

61. Hultgren R, Olofsson P, Wahlberg E. Gender differences in patients treated for critical limb ischemia. Eur J Vasc Endovasc Surg. 2005;29(3):295-300.

62. Lejay A, Schaeffer M, Georg Y, Lucereau B, Roussin M, Girsowicz E, et al. Gender related long-term differences after open infrainguinal surgery for critical limb ischemia. Eur J Vasc Endovasc Surg. 2015;50(4):506-12.

63. Hussain MA, Lindsay TF, Mamdani M, Wang X, Verma $\mathrm{S}, \mathrm{Al}-\mathrm{Omran} \mathrm{M}$. Sex differences in the outcomes of peripheral arterial disease: a population-based cohort study. CMAJ open. 2016;4(1):E124-E31.

64. Egorova N, Vouyouka AG, Quin J, Guillerme S, Moskowitz A, Marin M, et al. Analysis of gender-related differences in lower extremity peripheral arterial disease. J Vasc Surg. 2010;51(2):372-8.e1; discussion 8-9.

65. Wang J, He Y, Shu C, Zhao J, Dubois L. The effect of gender on outcomes after lower extremity revascularization. J Vasc Surg. 2017;65(3):889-906.e4.

66. Ziegler-Graham K, MacKenzie EJ, Ephraim PL, Travison TG, Brookmeyer R. Estimating the prevalence of limb loss in the United States: 2005 to 2050. Arch Phys Med Rehabil. 2008;89(3):422-9.
67. Lefebvre KM, Chevan J. The persistence of gender and racial disparities in vascular lower extremity amputation: an examination of HCUP-NIS data (2002-2011). Vasc Med (London, England). 2015;20(1):51-9.

68. Lane R, Ellis B, Watson L, Leng GC. Exercise for intermittent claudication. Cochrane Database Syst Rev. 2014;(7):Cd000990.

69. Murphy TP. Supervised exercise versus primary stenting for claudication resulting from aortoiliac peripheral artery disease: six-month outcomes from the claudication: exercise versus endoluminal revascularization (CLEVER) study. Circulation. 2012;125:130-EOA.

70. Aggarwal S, Moore RD, Arena R, Marra B, McBride A, Lamb B, et al. Rehabilitation therapy in peripheral arterial disease. Can J Cardiol. 2016;32(10 Suppl 2):S374-s81.

71. Bedenis R, Stewart M, Cleanthis M, Robless P, Mikhailidis DP, Stansby G. Cilostazol for intermittent claudication. Cochrane Database Syst Rev. 2014;(10):Cd003748.

72.• Kithcart AP, Beckman JA. ACC/AHA Versus ESC guidelines for diagnosis and management of peripheral artery disease: JACC guideline comparison. J Am Coll Cardiol. 2018;72(22):2789-80.

2018 US Guidelines for management of PAD.

73. Gerhard-Herman MD, Gornik HL, Barrett C, Barshes NR, Corriere MA, Drachman DE, et al. 2016 AHA/ACC guideline on the management of patients with lower extremity peripheral artery disease: executive summary. Vasc Med (London, England). 2017;22(3):Np1-np43.

74.• Halliday A, Bax JJ. The 2017 ESC guidelines on the diagnosis and treatment of peripheral arterial diseases, in collaboration with the European Society for Vascular Surgery (ESVS). Eur J Vasc Endovasc Surg. 2018;55(3):301-.

2018 European Guidelines for management of PAD.

\section{Publisher's Note}

Springer Nature remains neutral with regard to jurisdictional claims in published maps and institutional affiliations. 